\title{
VARIABLE QUEEN NUMBER IN ANT COLONIES: NO IMPACT ON QUEEN TURNOVER, INBREEDING, AND POPULATION GENETIC DIFFERENTIATION IN THE ANT FORMICA SELYSI
}

\author{
Michel Chapuisat, ${ }^{1}$ Samuel Bocherens, and Hervé Rosset \\ Department of Ecology and Evolution, Biology Building, University of Lausanne, 1015 Lausanne, Switzerland \\ ${ }^{1}$ E-mail: michel.chapuisat@ie-zea.unil.ch
}

\begin{abstract}
Variation in queen number alters the genetic structure of social insect colonies, which in turn affects patterns of kin-selected conflict and cooperation. Theory suggests that shifts from single- to multiple-queen colonies are often associated with other changes in the breeding system, such as higher queen turnover, more local mating, and restricted dispersal. These changes may restrict gene flow between the two types of colonies and it has been suggested that this might ultimately lead to sympatric speciation. We performed a detailed microsatellite analysis of a large population of the ant Formica selysi, which revealed extensive variation in social structure, with 71 colonies headed by a single queen and 41 by multiple queens. This polymorphism in social structure appeared stable over time, since little change in the number of queens per colony was detected over a five-year period. Apart from queen number, single- and multiple-queen colonies had very similar breeding systems. Queen turnover was absent or very low in both types of colonies. Single- and multiple-queen colonies exhibited very small but significant levels of inbreeding, which indicates a slight deviation from random mating at a local scale and suggests that a small proportion of queens mate with related males. For both types of colonies, there was very little genetic structuring above the level of the nest, with no sign of isolation by distance. These similarities in the breeding systems were associated with a complete lack of genetic differentiation between single- and multiple-queen colonies, which provides no support for the hypothesis that change in queen number leads to restricted gene flow between social forms. Overall, this study suggests that the higher rates of queen turnover, local mating, and population structuring that are often associated with multiplequeen colonies do not appear when single- and multiple-queen colonies still coexist within the same population, but build up over time in populations consisting mostly of multiple-queen colonies.
\end{abstract}

Key words._Breeding system, dispersal, genetic structure, microsatellites, relatedness, social evolution, social structure.

\section{Received June 13, 2003. Accepted January 28, 2004.}

Social insects exhibit a great variation in their social structure. In ants, the number of queens per colony varies among species, among populations, and even among colonies within the same population (Crozier and Pamilo 1996a; Pamilo et al. 1997; Ross 2001). These variations in social structure affect the genetic diversity within the colony, the relatedness among nestmates, and the architecture of potential kin-conflicts and kin-cooperation (Bourke and Franks 1995; Crozier and Pamilo 1996a). Hence, understanding the causes, correlates, and dynamics of variation in queen number is fundamental to gain a better understanding of social evolution.

The causes of variation in queen number are still controversial. Recent work in the fire ant Solenopsis invicta showed that variation in queen number is determined by a genetic polymorphism that makes workers accept or reject additional queens (Ross 1997; Keller and Ross 1998; Ross and Keller 1998; Krieger and Ross 2002). However, in other species queen number may be a phenotypically plastic trait strongly influenced by ecological factors (West-Eberhard 1989; Pedersen and Boomsma 1999a; Ingram 2002). Whatever the proximate determinants of queen number, the presence of multiple queens in the same colony seems paradoxical, because it decreases both the relatedness of workers to the brood they raise and the per capita reproductive output of queens (Hamilton 1964; Bourke and Franks 1995).

However, various ecological and demographic factors may select for accepting additional queens. Strong ecological constraints limiting independent colony founding by queens, such as nest-site limitation, predation, or competition from older colonies, should favor the acceptance of new daughter queens into their natal colonies (Nonacs 1988; Pamilo 1991a; Herbers 1993; Bourke and Franks 1995; Keller 1995). In line with this argument, the habitat saturation hypothesis predicts that queen number should increase over time once all potential nest sites or territories are occupied by ant colonies (Herbers 1986; Bourke and Franks 1995; Pedersen and Boomsma 1999a). In addition, members of multiple-queen colonies may also benefit from higher growth rates, larger colony size, increased genetic diversity, increased colony survival, longer life-span of the colony, and better short-range colonization ability (Hölldobler and Wilson 1977; Bourke and Franks 1995; Keller 1995).

The theory predicts that the shift from single- to multiplequeen colonies should often be associated with other changes in queen turnover, mating system, and dispersal (Bourke and Franks 1995; Pamilo et al. 1997; Ross 2001). Usually, singlequeen colonies do not accept replacement queens, and the life span of the colony matches the life span of the queen. In contrast, multiple queen colonies accept replacement queens and may have high rates of queen turnover (Hölldobler and Wilson 1990; Bourke and Franks 1995; Keller and Genoud 1997). Single-queen colonies typically produce queens and males that participate in extensive mating flights and mate away from the nest. After dispersal, queens found new colonies independently, with no assistance from workers, or by temporarily parasitizing the nests of other ant species (Hölldobler and Wilson 1990). Therefore, single-queen colonies are predicted to form large panmictic populations 
with no inbreeding, no isolation by distance, and minimal genetic structure above the nest level (Bourke and Franks 1995; Crozier and Pamilo 1996a; Pamilo et al. 1997). In contrast, queens from multiple-queen colonies often mate close to or in their natal nest. After mating, they stay in their natal nest or form new colonies by budding, a process whereby queens with workers depart from a colony and establish a new colony in the vicinity (Hölldobler and Wilson 1990). Overall, local mating and restricted dispersal should result in significant deficiency of heterozygotes, isolation by distance, and genetic structuring above the level of the nest in populations of multiple-queen colonies (Bourke and Franks 1995; Crozier and Pamilo 1996a; Pamilo et al. 1997).

A large body of empirical data confirms that changes in social structure are often associated with changes in queen turnover, mating system, and dispersal. An absence of queen turnover coupled with queen life spans over 20 years has been documented in several ant species with single-queen colonies (Pamilo 1991b; Keller and Genoud 1997). In contrast, short queen life spans are common in multiple-queen colonies (Keller and Genoud 1997), with annual rates of queen turnover close to $50 \%$ in several species of Myrmica ants (Seppä 1994; Evans 1996; Pedersen and Boomsma 1999a). Populations with single-queen colonies are usually in Hardy-Weinberg equilibrium and show little genetic differentiation above the level of the nest, which suggests that queens and males disperse widely (Crozier and Pamilo 1996a; Pamilo et al. 1997; Ross 2001). In contrast, significant deficiencies of heterozygotes and isolation by distance have been detected in several populations with multiple-queen colonies. This indicates that effective dispersal of queens and males is restricted in these populations, which results in microgeographical genetic structure but does not necessarily imply high rates of close inbreeding (mating between closely related individuals) if queen number is high (Chapuisat et al. 1997; Pamilo et al. 1997; Chapuisat and Keller 1999; Ross 2001). However, exceptions to this general pattern do exist. For example, queen turnover occasionally occurs in monogynous (single-queen colonies) populations of ants (Heinze and Keller 2000), and significant levels of inbreeding were associated with signs of restricted dispersal of females in monogynous populations of Formica exsecta (Sundström et al. 2003).

Interestingly, differences in mating location, dispersal, and mode of colony founding may restrict gene flow between single- and multiple-queen colonies. Variation in social structure may thus result in genetic differentiation between the social forms, and it has even been suggested that this process might lead to sympatric speciation (West-Eberhard 1986; Crozier and Pamilo 1996b; Shoemaker and Ross 1996). A recent model also showed that green-beard selection based on the social discrimination of tags may lead to reproductive isolation (Hochberg et al. 2003). In line with these ideas, detailed genetic studies of the fire ant Solenopsis invicta revealed that gene flow between social forms is restricted, resulting in weak but significant genetic differentiation for microsatellite markers and strong differentiation for mitochondrial DNA (Shoemaker and Ross 1996; Ross et al. 1999). In contrast, no differentiation between social forms was detected in Leptothorax rugatulus, based on both microsatellite and mitochondrial markers (Rüppell et al. 2003). Hence, more empirical data are needed to assess whether variation in social structure is generally associated with genetic differentiation.

The correlates of variation in queen number and the resulting genetic differentiation between social forms have usually been studied by comparing populations with single- or multiple-queen colonies (Pamilo et al. 1997; Ross 2001). This is a derived situation, and the coexistence of the two colony types in the same site better reflects the primary situation in which multiple-queen colonies evolved from single-queen ones (Keller and Chapuisat 2002). Therefore, it remains unclear whether a change in the social structure immediately promotes differences in the mating system, dispersal, and genetic structure, or whether the shift in the breeding system develops progressively in isolated populations consisting mostly or exclusively of multiple-queen colonies. To resolve this issue, it is important to study within-population variation in queen number, queen turnover, mating system, and dispersal, as well as genetic differentiation between sympatric social forms. Data on the dynamics of queen number and on variation in social structure over time are also needed to get a clearer picture of how complex social structures appear and are maintained.

In this study, we examine the genetic consequences of variation in social structure within a large population of the ant Formica selysi. Specifically, on the basis of microsatellite data from several generations of workers, we characterize how the social structure varies among colonies and over time. We then examine whether variation in social structure correlates with differences in queen turnover, mating system, gene flow, and genetic structuring above the nest level. Finally, we test for genetic differentiation between the singleand multiple-queen social forms.

\section{Materials And Methods}

Study Species and Study Site

Formica selysi is a pioneer species that colonizes bare sandy and stony ground, as well as open steppes. In the Alps, $F$. selysi is found in xeric habitat along large rivers, where it is locally very abundant. It nests in the soil and feeds on various arthropod prey and on honeydew from aphids (Keller and Zettel 2001a). Formica selysi is well adapted to resist occasional floods, and nests can survive under water for several days (Lude et al. 1999).

Our study site is an alluvial plain located along the river Rhône between Sierre and Susten in the central Valais, Switzerland (the '"Rottensand,', longitude $7^{\circ} 36^{\prime} 30^{\prime \prime} \mathrm{E}$, latitude $46^{\circ} 18^{\prime} 30^{\prime \prime} \mathrm{N}$, altitude $565 \mathrm{~m}$ ). The plain is a mosaic of pine forest, steppe areas dominated by the grass Stipa pennata, and floodplains of bare sand and gravel. Parts of this habitat are periodically affected by floods from the river Rhône. Floods occurred in autumn 1993 and 2000, covering large areas with sand and gravel, and locally causing severe erosion. Most samples were taken in mature steppes that had not been affected by recent floods and where the density of nests was high (Keller and Zettel 2001b). A few colonies were also sampled on a river embankment, in open pine forest or in the high water bed of the river. 


\section{Sampling}

Adult workers were sampled from 112 nests in spring 2000 and 2001. Flat stones were placed over the nests to facilitate subsequent sampling. Nests were mapped with a global positioning system (GPS, Garmin, Olathe, KS) and a metric rope for short distances. The sampling area was approximately $1500 \mathrm{~m}$ long and $500 \mathrm{~m}$ wide. To get more insight into spatial differentiation, we sampled nests in four geographical sectors separated by 100 to $300 \mathrm{~m}$ of habitat slightly less suitable for the ants. The distance between sampled nests ranged from one to $1458 \mathrm{~m}$.

To estimate whether queen number varies over time in the population, the social structure of a small set of nests sampled in spring 1996 was compared to the social structure of the larger set of nests collected in 2000 and 2001. The 1996 sample consisted of adult workers from 25 nests located in an area approximately $430 \mathrm{~m}$ long and $200 \mathrm{~m}$ wide. To estimate yearly changes in social structure within colonies, two types of brood samples were taken from part of the 112 nests in which adults had been collected. First, worker brood (larvae and pupae destined to become workers) was collected twice from a subsample of 17 nests, in summer 2000 and again in summer 2001. Second, worker brood was sampled once from a subsample of 43 nests in summer 2000 or 2001, a few months after adult workers had been sampled from the same nests. Eggs of Formica are laid in spring and summer, and no brood overwinters (Forel 1920; Gösswald 1989). The first new workers emerge in June in our study population, and Formica workers live for a couple of years, at most (Gösswald 1989). Hence, adult workers sampled in spring are at least one year older than the worker brood sampled in summer, and samples of adults and brood can be used to estimate yearly changes in social structure and genetically effective queen turnover (see below). Sampled individuals were stored in absolute ethanol until genetic analysis.

\section{Microsatellite Analysis}

For each of the 112 nests sampled in 2000 and 2001, eight adult workers and up to 16 worker brood (if any) were genotyped at nine microsatellite markers. DNA was extracted by incubating three crushed legs from adults or a small piece of tissue from brood in $250 \mu \mathrm{L}$ of $5 \%$ Chelex (Sigma-Aldrich, Steinheim, Germany) at $95^{\circ} \mathrm{C}$ for $20 \mathrm{~min}$. We used three microsatellite markers originally developed for Formica paralugubris (FL12, FL20, and FL21; Chapuisat 1996) and six markers developed for Formica exsecta (FE7, FE8, FE16, FE17, FE19, and FE38; Gyllenstrand et al. 2002). The markers varied greatly in terms of genetic diversity in $F$. selysi, with a mean of five alleles and a mean expected heterozygosity of 0.47 (Table 1). Taken together, this panel of nine markers is a powerful tool to reveal the social structure of nests and the fine-scale genetic structure of the population. Two additional markers had to be discarded because they were difficult to score (FE48; Gyllenstrand et al. 2002) or had null alleles (FL29; Chapuisat 1996). Primers were labeled with HEX, NED, and 6-FAM fluorescent dyes and the amplification products were analyzed on an ABI (Applied Biosystems, Foster City, CA) Prism 377 XL DNA sequencer. Alleles were scored with the Genescan (ABI Prism) software.
TABle 1. Genetic diversity of microsatellite markers in Formica selysi. The number of alleles (NA), frequency of the most common allele $(F C A)$ and expected heterozygosity $\left(H_{e}\right)$ are presented. Allele frequencies were calculated weighting nests equally. The sample size was 1444 individuals from 112 nests.

\begin{tabular}{lrcc}
\hline \hline Locus & $N A$ & $F C A$ & $H_{e}$ \\
\hline FL12 & 3 & 0.59 & 0.51 \\
FL20 & 4 & 0.86 & 0.24 \\
FL21 & 11 & 0.44 & 0.72 \\
FE7 & 4 & 0.56 & 0.59 \\
FE8 & 2 & 0.99 & 0.03 \\
FE16 & 3 & 0.58 & 0.49 \\
FE17 & 6 & 0.31 & 0.75 \\
FE19 & 2 & 0.66 & 0.45 \\
FE38 & 10 & 0.74 & 0.43 \\
\hline
\end{tabular}

For each of the 25 nests sampled in 1996, 10 adult workers were genotyped at three microsatellite markers (FL12, FL20, and FL21) as described in Chapuisat (1996).

\section{Genetic Data Analysis}

The social structure was assessed by measuring relatedness among nestmate workers with the method of Queller and Goodnight (1989), as implemented in the computer program Relatedness 5.0.4 (http://www.gsoftnet.us/GSoft.html). Nests were weighted equally. The standard error of the average relatedness was obtained by jackknifing over nests (jackknifing over loci yielded smaller standard errors). The standard error and $95 \%$ confidence interval of relatedness within single nests were determined by jackknifing over loci. The social structure of nests was further determined by examining the arrays of genotypes and by testing the pedigree relationships with the likelihood approach implemented in the computer program Kinship 1.3.1 (Goodnight and Queller 1999; http://www. gsoftnet.us/GSoft.html). The effective number of queens $(f)$ was estimated from the relatedness among workers $(r)$ with the formula $f=3 /(4 r)$. This is the number of unrelated, singlemated, and equally reproducing queens that in a randomly mating population would produce offspring with genetic diversities equal to the one observed in the study colonies. Alternatively, if queens stay in their natal nests and mate with unrelated males, the relatedness among queens is equal to the relatedness among workers. Then, assuming a stable number of queens, the effective number of related queens is estimated as $(3-r) /(3 r)$ (e.g. Pamilo 1991a).

The genetically effective queen turnover $(Q)$ was estimated with the following formula:

$$
Q=1-\left[2 r_{a b} /\left(r_{a a}+r_{b b}\right)\right],
$$

where $r_{a b}$ is the relatedness between adult workers and worker brood, $r_{a a}$ is the relatedness among adult workers, and $r_{b b}$ is the relatedness among worker brood (Evans 1996). This measure of genetic turnover is close to zero if the same set of queens has produced the adults and the current cohort of brood, because in that case the relatedness between cohorts is equal to the relatedness within cohorts. In contrast, $Q$ is greater than zero if queens and their mates have been replaced by genetically distinct individuals, because in that case the relatedness between cohorts becomes smaller than the relatedness within cohorts. Confidence intervals of the genetically 
effective queen turnover estimates were obtained by bootstrapping over colonies 1000 times.

The mating system and genetic differentiation among sectors were investigated by applying a multilevel hierarchical $F$-analysis of variance to the worker genotypes (Weir and Cockerham 1984; Weir 1996). To control for the nonindependence of individuals from the same colony, individual workers were nested into their respective colonies, and colonies were nested into sectors. The within sector $\left(F_{\text {ind-sect }}\right)$ and overall $\left(F_{\text {ind-tot }}\right)$ inbreeding coefficients reflect the deficiency of heterozygotes due to nonrandom mating within the sectors and within the total population, respectively, and $F_{\text {sect-tot }}$ estimates the amount of genetic differentiation (allele frequency differences) among the sectors. The hierarchical analysis was performed with the computer program Genetic Data Analysis 1.0 (Lewis and Zaykin 1999). Confidence intervals were obtained by bootstrapping over loci 5000 times. To detect potential differences in breeding systems, each social form (single- or multiple-queen colonies) was analyzed separately, as well as together.

We examined whether there was isolation by distance (a positive correlation between geographical distance and genetic differentiation) in both single- and multiple-queen colonies, across all sectors and per sector. We calculated $F_{\mathrm{ST}}$ for all pairs of nests, and tested the correlation between this matrix of genetic differentiation and the matrix of geographical distances in a Mantel test with 5000 permutations, using Spearman rank correlation coefficients as implemented in the computer program Genepop 3.1a (Raymond and Rousset 1995; http://www. biomed.curtin.edu.au:80/genepop/index.html). We also tested whether nests of similar social structure were spatially clustered by examining the spatial autocorrelation of single-nest relatedness (Legendre and Fortin 1989), using the computer program R 3.02 (http://www.fas.umontreal.ca/BIOL/Casgrain/en/labo/ R/index.html).

Genetic differentiation between the social forms was tested for in two slightly different hierarchical $F$-analyses of variance. First, a three-level analysis was performed, with individuals nested in colonies, colonies in social forms (singleor multiple-queen colonies), and social forms in the total population. Second, a four-level analysis was performed, with individuals nested in colonies, colonies in social forms, social forms in sectors, and sectors in the total population. The first analysis tests for an overall differentiation between the social forms, and the second analysis examines whether there is differentiation between the social forms within the sectors.

\section{RESULTS}

\section{Social Structure}

The 112 nests sampled in 2000 and 2001 varied greatly in their social structure (Fig. 1). The average relatedness among nestmate workers was $0.54 \pm 0.03$ (mean $\pm \mathrm{SE}$ ). However, few nests had an average relatedness close to this population mean. The distribution of single-nest relatedness was strongly bimodal, with a peak centered on 0.75 and a peak centered on 0.15 (Fig. 1). The social structure of nests was also determined by inspecting the arrays of genotypes in each nest and by testing the likelihood of various pedigree relationships. Out of the 112 nests sampled, 71 (63\%) had genotype

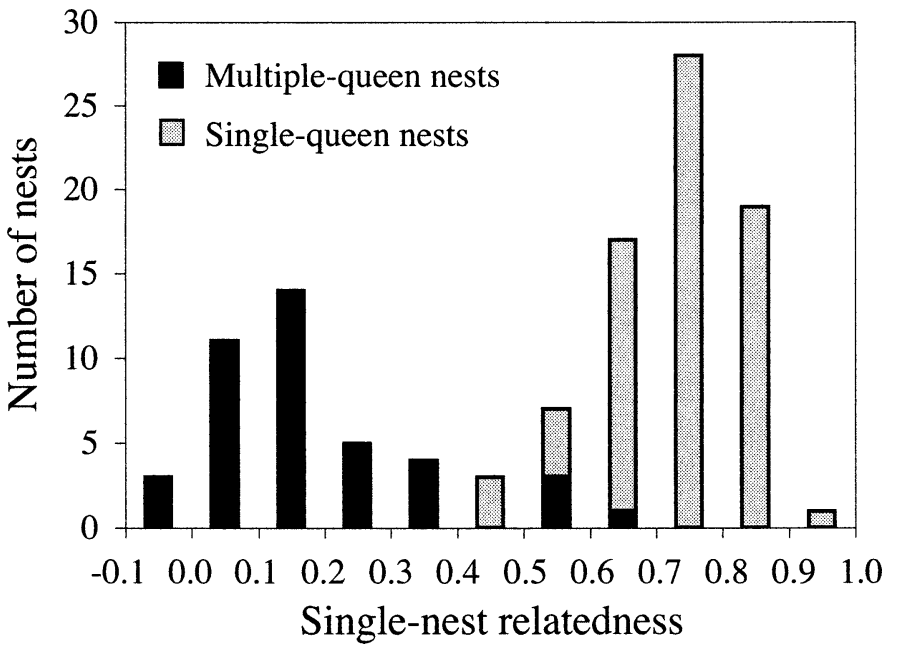

FIG. 1. Distribution of single-nest relatedness estimates (the relatedness among workers within each nest) in a large population of Formica selysi. The social structure of nests (single- or multiplequeen) was inferred from the arrays of genotypes.

arrays consistent with a single queen, usually mated to a single male, although double mating of the queen was detected in seven $(10 \%)$ of those 71 nests. The average relatedness in colonies classified as having a single-queen was $0.732 \pm 0.012$, in good agreement with theoretical expectations for this social structure (Bourke and Franks 1995). The remaining 41 nests had multiple queens. The average relatedness in those nests was $0.176 \pm 0.027$. This relatedness corresponds to an effective queen number of 4.3 if both the queens and males are unrelated, and of 5.3 if queens are as related as workers.

\section{Changes in Social Structure}

At the population level, the social structure of the set of nests sampled in 1996 did not differ significantly from the social structure of the set of nests sampled four years later. In the 1996 sample, the average relatedness among nestmate workers was $0.437 \pm 0.071$. Out of the 25 sampled nests, 12 (48\%) had genotypes consistent with a single queen, and the remaining 13 had multiple queens. Overall, the proportion of nests with a single queen was lower in the 1996 than in the 2000-2001 sample, but this difference was not significant (Fisher's exact test, $P=0.18$ ). Moreover, the distribution of single-nest relatedness values did not differ significantly between the two samples (Mann-Whitney $U$ test, $Z=-1.68$, $P=0.09$ ).

At the colony level, the social structure of nests appeared stable in 2000 and 2001. Very little yearly change in effective queen number was detected. Two different analyses were performed, one comparing the brood sampled in two consecutive years, and the other comparing the samples of adults and brood collected during the same year. The first analysis suggests that the effective number of queens did not change significantly in the 17 nests from which brood was sampled during two consecutive years. The average relatedness in the brood was $0.523 \pm 0.072$ in 2000 and $0.484 \pm 0.076$ in 2001 . The relatedness within single nests did not differ significantly 
TABLE 2. Genetically effective rate of queen turnover $(Q)$. The number of nests $(N)$ and the nestmate relatedness among adults $\left(r_{a a}\right)$, among brood $\left(r_{b b}\right)$, and between adults and brood $\left(r_{a b}\right)$ are presented.

\begin{tabular}{lcccccc}
\hline \hline & & & & \multicolumn{2}{c}{ Queen turnover } \\
\cline { 5 - 7 } \multicolumn{1}{c}{ Colonies } & $N$ & $r_{a a}$ & $r_{b b}$ & $r_{a b}$ & $Q$ & $95 \%$ CI \\
\hline Single-queen & 24 & 0.752 & 0.756 & 0.752 & 0.003 & $-0.028 ; 0.039$ \\
Multiple-queen & 19 & 0.231 & 0.276 & 0.247 & 0.025 & $-0.127 ; 0.193$ \\
All & 43 & 0.522 & 0.544 & 0.529 & 0.008 & $-0.032 ; 0.056$ \\
\hline
\end{tabular}

between the two years when considering all nests (pairwise $t$-test, $\mathrm{df}=16, t=1.26, P=0.23)$, only single- $(\mathrm{df}=8, t$ $=0.75, P=0.48$ ) or only multiple-queen nests (pairwise $t$ test, $\mathrm{df}=7, t=0.98, P=0.36$ ). For each nest, the confidence interval of the single-nest relatedness estimate from the 2000 cohort overlapped broadly with the one from the 2001 cohort.

The second analysis suggests that the effective queen number did not change significantly in 42 out of the 43 nests in which adults and brood were sampled on the same year. The average relatedness was $0.522 \pm 0.047$ for the adult workers and $0.544 \pm 0.047$ for the worker brood. Overall, single-nest relatedness of the adults and of the brood did not differ significantly when considering all nests (pairwise $t$-test, df $=$ $42, t=-0.84, P=0.41)$, only single- $(\mathrm{df}=23, t=-0.20$, $P=0.84)$, or only multiple-queen nests ( $\mathrm{df}=18, t=-0.825$, $P=0.42$ ). In all but one nest, the confidence interval of the single-nest relatedness estimate from adults overlapped broadly with the one from the brood. In the nest where the confidence intervals did not overlap, five matrilines were detected in the adults and only one in the brood, which indicates a reduction in queen number.

\section{Queen Turnover}

The genetically effective queen turnover was estimated from the relatedness within and between cohorts of workers (Table 2). Overall, queen turnover was only $0.8 \%$, with a $95 \%$ confidence interval overlapping with zero and reaching an upper limit of $5.6 \%$. In the 24 single-queen colonies analyzed, the relatedness within and between cohorts was 0.75 , and the queen turnover was effectively zero. Direct inspection of genotypes further confirmed that no queen replacement had occurred in those colonies. Surprisingly, the queen turnover within the 19 multiple-queen colonies analyzed was also very low, with an estimate of $2.5 \%$. The $95 \%$ confidence interval overlapped with zero, but reached an upper limit of $19 \%$, which indicates that the queen turnover might be slightly higher in multiple-queen colonies than in single-queen ones. However, overall the genetically effective yearly rate of queen replacement was very small in both types of colonies.

\section{Mating System and Dispersal}

A small but significant deficiency of heterozygotes was detected within sectors $\left(F_{\text {ind-sect }}=3.6 \%\right.$; Table 3$)$. Interestingly, this inbreeding coefficient was similar for single- and multiple-queen colonies, with small but largely overlapping confidence intervals (Table 3 ). Overall, the amount of genetic differentiation among the sectors was very small $\left(F_{\text {sect-tot }}=\right.$ $0.2 \%$ ) and not significantly different from zero (Table 3 ). Single- and multiple-queen colonies showed similarly low levels of differentiation among sectors, with largely overlapping confidence intervals, and upper limits of the $95 \%$ confidence interval of $1.5 \%$ and $1.7 \%$, respectively. However, the differentiation among sectors was significant for multiplequeen colonies only, which might indicate a slightly more pronounced structure in this social form (Table 3). Because there was only minimal differentiation among sectors, the overall inbreeding coefficient $\left(F_{\text {ind-tot }}\right)$ was very similar to the one measured within sectors ( $F_{\text {ind-sect }}$; Table 3$)$.

No isolation by distance was detected in the population (Table 4). There was no positive correlation between geographical distance and genetic differentiation between pairs of nests, whatever the social structure of colonies (single- or multiple-queen) and spatial scale of analysis (within sectors or across all sectors). These results should be considered with some caution, because $F_{\mathrm{ST}}$ values between pairs of nests have large errors. However, when considered together, these data suggest that single- and multiple-queen colonies are very similar with respect to mating system and gene flow among nests. Both show small levels of inbreeding and minimal genetic differentiation above the level of the nest, with no sign of isolation by distance.

\section{Spatial Distribution of Social Forms}

Nests of similar social structure tended to be clustered, as shown by the significant spatial autocorrelation of single-nest relatedness. The spatial autocorrelation coefficient showed an alternation of positive and negative values, which indicates patchiness (Legendre and Fortin 1989). Using 20 equifrequent classes of distances, the Moran's $I$ autocorrelation co-

TABLE 3. Inbreeding coefficient within the sectors $\left(F_{\text {ind-sect }}\right)$, genetic differentiation among the sectors $\left(F_{\text {sect-tot }}\right)$ and overall deficiency of heterozygous $\left(F_{\text {ind-tot }}\right)$. The $95 \%$ confidence intervals are given in parentheses, and $N$ is the number of nests.

\begin{tabular}{lrccc}
\hline \hline \multicolumn{1}{c}{ Colonies } & $N$ & $F_{\text {ind-sect }}$ & $F_{\text {sect-tot }}$ & $F_{\text {ind-tot }}$ \\
\hline Single-queen & 71 & $0.033(0.003 ; 0.067)$ & $0.003(-0.008 ; 0.015)$ & $0.032(0.003 ; 0.065)$ \\
Multiple-queen & 41 & $0.046(0.010 ; 0.087)$ & $0.010(0.004 ; 0.017)$ & $0.044(0.008 ; 0.084)$ \\
All & 112 & $0.036(0.010 ; 0.066)$ & $0.002(-0.004 ; 0.007)$ & $0.035(0.010 ; 0.064)$ \\
\hline
\end{tabular}


TABLE 4. Tests of isolation by distance. The number of nests $(N)$, the correlation between the matrices of $F_{\mathrm{ST}}$ and geographical distances, and the significance of isolation by distance in the Mantel test $(P)$ are presented. Values per sector are separated by slashes. Dash indicates value not available.

\begin{tabular}{llll}
\hline \hline \multicolumn{1}{c}{ Colonies } & \multicolumn{1}{c}{ Matrix correlation } & $P$ \\
\hline Single-queen all sectors & 71 & 0.01 & 0.40 \\
Single-queen per sector & $1 / 30 / 19 / 21$ & $-/-0.07 / 0.05 /-0.29$ & $-10.81 / 0.35 / 0.86$ \\
Multiple-queen all sectors & 41 & -0.1 & 0.87 \\
Multiple-queen per sector & $10 / 12 / 13 / 6$ & $-0.13 /-0.1 /-0.09 /-0.17$ & $0.69 / 0.69 / 0.78 / 0.65$ \\
All colonies all sectors & 112 & -0.11 & 0.62 \\
\hline
\end{tabular}

efficient was highly positive and significant $(I=0.39, P<$ 0.001 ) for the first class of distances (up to 33 meters), and significantly negative and positive values alternated for larger distance classes. The correlogram was globally significant, with five classes conserving significant autocorrelation coefficients after a Bonferroni correction. Hence, neighboring nests tended to have a similar social structure, and overall single- and multiple-queen nests had a tendency to be clustered in relatively small patches. The proportion of singleand multiple-queen colonies also differed significantly among sectors ( $\mathrm{df}=3, \chi^{2}=17.8, P=0.0005$ ), as did the distribution of single-nest relatedness (Kruskal-Wallis test, df $=3, H=13.8, P=0.003$ ), which further shows that nests with alternative social structures have a heterogenous spatial distribution.

\section{Genetic Differentiation between the Social Forms}

There was no genetic differentiation between single- and multiple-queen colonies. In a three-level analysis, with individuals nested in colonies and colonies in social forms, the coefficient of differentiation between social forms ( $\left.F_{\text {social form-total }}\right)$ was -0.005 , with a $95 \%$ confidence interval ranging from -0.007 to -0.004 . The slightly negative estimate suggests that allele frequencies tend to be more similar between social forms than expected by chance, a result that might be due to the small amount of genetic differentiation among the sectors. Indeed, in a four-level analysis that controlled for the effect of genetic differentiation among sectors by having individuals nested in colonies, colonies in social forms and social forms in sectors, the coefficient of differentiation between social forms within sectors $\left(F_{\text {social form-sector }}\right)$ was -0.001 , with a $95 \%$ confidence interval ranging from -0.007 to 0.006 .

\section{DISCUSSION}

Data on the behavioral and genetic correlates of changes in social structure are needed to obtain a better understanding of social evolution (Bourke and Franks 1995; Ross 2001). In this study, a detailed genetic analysis at nine microsatellite markers revealed that the social structure of nests varied greatly within a population of the ant Formica selysi. About two-thirds (63\%) of the 112 nests analyzed were headed by a single queen, usually mated to a single male, and the rest of the nests $(37 \%)$ had multiple queens. In these polygynous nests, the effective number of queens was 4.3 , and the actual number of queens was likely to be much greater than this value if queens were related or if their shares of reproduction were unequal (e.g. Chapuisat and Crozier 2001). Few nests had relatedness values consistent with having two queens, and some had very low relatedness values indicating that they had many queens. Hence, there is a pronounced polymorphism in social structure within this population, with nests containing either one or from several to many queens. Such intraspecific polymorphism in queen number seems to be common in the genus Formica, where it occurs both among (Rosengren et al. 1993; Sundström 1993) and within populations (Goropashnaya et al. 2001).

The number of queens per colony appeared stable over time in F. selysi, at both the population and the colony level. At the population level, we detected no change in queen number over a five-year period. More single-queen nests were sampled in 2000 and 2001 than in 1996, although this difference was not significant and may be entirely due to sampling errors. At the colony level, very little yearly change in queen number was detected. No additional queen was adopted in the 24 single-queen colonies that were surveyed. The number of queens also appeared stable in the multiple-queen colonies: in the 43 colonies surveyed, the only significant change was an apparent loss of queens in one colony. Together, these data do not support the hypothesis that queen number increases over time due to increased habitat saturation, at least in the time period investigated. More long-term data are required to determine whether this apparent stability in queen number and coexistence of social forms results from diversifying selection, weak selection, or selection pressures fluctuating over space or time.

So far, no study has followed queen number over long periods of time, and evidence for an effect of habitat saturation is mostly indirect. The number of queens per nest increased along a density gradient in an invading population of Linepithema humile, which is consistent with the habitat saturation hypothesis (Ingram 2002). Higher queen number per colony in old than in young habitat was also detected in one population of Myrmica sulcinodis (Pedersen and Boomsma 1999a) and in two species of Formica ants (Seppä et al. 1995), but not in three other ant species (Seppä et al. 1995). Controlled experiments in which supplementary nest sites were added had variable outcomes. The number of queens per nest decreased when nests were added in a population of Leptothorax longispinosus, as predicted by the habitat saturation hypothesis (Herbers 1986). However, the relatedness among workers decreased after nest supplementation in two populations of Myrmica punctiventris, whereas simultaneously adding both food and nest sites increased relatedness in one of the populations but decreased it in the other (Herbers and Banschbach 1999; DeHeer et al. 2001). Overall, the impact of habitat saturation on social structure seems to be variable, and probably depends on details of the ecology of 
the species, such as nest site availability, food resources, demographic regulation, and habitat stability at various scales.

Apart from the difference in queen number, single- and multiple-queen colonies had very similar breeding systems. The genetically effective queen turnover was very low in both social forms, although perhaps slightly higher in multiple than in single-queen colonies. No queen was replaced in the 24 single-queen colonies surveyed. This finding is in agreement with the common view that queen replacement is very rare or absent in single-queen colonies of ants (Pamilo 1991b; Bourke and Franks 1995). Moreover, the rarity of queen turnover in perennial nests of $F$. selysi suggests that queens have long life spans that probably match the life span of the colony. In line with this result, queen life spans greater than 20 years have been recorded in Formica exsecta and in other monogynous populations of ants (Pamilo 1991b; Keller 1998). More surprisingly, the genetically effective queen turnover was also low in multiple-queen colonies, with a mean rate of only $2.5 \%$. This low queen turnover stands in sharp contrast to estimates of genetically effective queen turnover in polygynous colonies of several species of Myrmica, which ranged between 40\% and 60\% (Seppä 1994; Evans 1996; Pedersen and Boomsma 1999a). In Leptothorax acervorum, a high turnover of queens was also indicated by the elevated frequency of sexual progeny that was not the offspring of the extant queen (Bourke et al. 1997). The surprisingly low rate of queen turnover in polygynous colonies of $F$. selysi suggests that queens in this type of colony do also have long life spans. If the number of queens is stable over time, an average queen turnover of $2.5 \%$ roughly corresponds to a mean queen life span of 40 years. This estimate is sensitive to errors in the estimate of queen turnover, and when we use the upper limit of the $95 \%$ confidence interval of the queen turnover the queen life span estimate reduces to 5.2 years. This minimal estimate is still higher than queen life span in six other species of polygynous ants, which was only 1.6 years on average (Keller and Genoud 1997; Keller 1998). The similarly long life span of queens in single- and multiple-queen colonies of $F$. selysi suggests that these queens have been subject to similar patterns of extrinsic mortality over evolutionary time, in contrast to the sharp difference observed between monogynous and polygynous species (Keller and Genoud 1997).

The mating system of single- and multiple-queen colonies also appeared to be very similar. Both types of colonies showed a small but significant deficiency of heterozygotes. This positive inbreeding coefficient in the absence of microgeographical genetic structure suggests that a small proportion of the queens mate with closely related males. For example, an inbreeding coefficient of 0.036 corresponds to approximately $13 \%$ of sibling matings, given the relation $F=$ $D /(4-3 D)$, where $D$ is the frequency of sibling mating (Suzuki and Iwasa 1980). Our field observations of mating behavior suggest that at least part of the males and females mate close to the nest, which may result in mating among relatives. We observed small numbers of males and females flying to the tops of pine trees close to their colonies. Males performed patrol flights around the trees and mating took place on the trees. Numerous such mating sites occur within the study area (M. Chapuisat, pers. obs.).
Single- and multiple-queen colonies showed little genetic differentiation above the level of the nest, with no or minimal differentiation among sectors and no sign of isolation by distance. This lack of spatial differentiation suggests that gene flow is high enough to homogenize allele frequencies over small (within sectors) and intermediate (among sectors) spatial scales. It also indicates that neighboring nests represent independent colonies that do not exchange high numbers of workers. However, the absence of marked differentiation at nuclear markers does not necessarily mean that queens from single- and multiple-queen colonies have identical dispersal strategies. Indeed, the slightly higher level of differentiation among sectors in multiple-queen colonies may indicate a somewhat more restricted dispersal in this social form, and the spatial clustering of nests with similar social structure suggests that multiple-queen colonies often arise from budding of nearby polygynous colonies. Even if queens from multiple-queen colonies found new colonies by budding and only disperse over short distances, gene flow through males may be sufficient to erase the genetic signature of colony budding, as has been documented in Rhytidoponera metallica (Chapuisat and Crozier 2001) and Leptothorax rugatulus (Rüppell et al. 2003). The hypothesis that female dispersal is restricted in multiple-queen colonies of $F$. selysi might be tested by examining whether there is a much stronger local differentiation at mitochondrial markers than at nuclear markers, as has been documented in several polygynous ant populations (Ross 2001; Rüppell et al. 2003).

Overall, multiple-queen colonies in this population of $F$. selysi did not show clear signs of the shift in mating system and genetic structuring that is usually associated with the presence of multiple queens in other ant populations (Bourke and Franks 1995; Ross 2001). Compared to single-queen colonies, multiple-queen colonies did not appear to have a higher level of inbreeding resulting from local mating, nor did they show signs of restricted dispersal of both sexes and isolation by distance over small spatial scales. This result contrasts with the frequent occurrence of local mating, population differentiation, and isolation by distance in polygynous ant populations from species belonging to the genera Formica (Pamilo 1982, 1983; Sundström 1993; Chapuisat et al. 1997; Chapuisat and Keller 1999), Myrmica (Seppä and Pamilo 1995; Pedersen and Boomsma 1999a,b; van der Hammen et al. 2002) and Solenopsis (Ross et al. 1997, 1999).

Importantly, all these populations with pronounced shifts in mating and dispersal strategies are predominantly composed of colonies with high numbers of queens per nest. In contrast, both single- and multiple-queen colonies coexist in the $F$. selysi population under study. Comparing the two types of systems strongly suggests that the shift in the mating system and genetic structure that is typically associated with multiple queening does not appear when multiple-queen colonies first emerge and still coexist with single-queen colonies, but progressively develops in isolated populations consisting mostly or exclusively of multiple-queen colonies. A simple explanation for this pattern would be that ongoing gene flow between social forms prevents the emergence of distinct genetic structures when single and multiple-queen colonies exist in the same site. In the $F$. selysi population under study, periodic habitat perturbations by floods may also 
result in repeated events of extinction and recolonization of small habitat patches, which might prevent the building up of divergent genetic structures in each social form.

There was no differentiation between single- and multiplequeen colonies of $F$. selysi. Because the analysis involved large numbers of nests and loci, the confidence intervals of the estimator of differentiation are very small, which ensured that even a slight amount of differentiation between the social forms would have been detected with high power. Two nonmutually exclusive processes may explain this lack of differentiation. First, the shifts between single- and multiplequeen colonies may be too recent or too frequent for genetic differentiation to have built up. Second, ongoing gene flow between the social forms may be sufficient to homogenize allele frequencies at nuclear markers. Significant gene flow between social forms is fully consistent with the fact that ants in single- and multiple-queen colonies have similar mating systems, with low inbreeding coefficients and no differentiation above the level of the nest. Moreover, even a small rate of migration between single- and multiple-queen colonies may be sufficient to prevent differentiation if the effective population size of each social form is high (Wright 1943). Whatever the causes of the lack of differentiation, our study does not support the hypothesis that changes in social structure lead to genetic differentiation and promote speciation when both social forms coexist in the same site. Significant differentiation between social forms was found in Solenopsis invicta. Interestingly, in this species, single- or multiplequeen colonies exist in distinct populations and the social structure is under a simple genetic control that restricts gene flow between social forms (Shoemaker and Ross 1996; Ross et al. 1999; Krieger and Ross 2002). The contrast between $F$. selysi and $S$. invicta suggests that two processes may lead to genetic differentiation between social forms. First, genetic differentiation may build up over time once the populations contain predominantly single- or multiple-queen colonies that have diverged in their mating and dispersing habits. Second, differentiation between single- and multiple-queen colonies may be due to special genetic mechanisms restricting gene flow, such as green-beard alleles. Hence, differentiation between social forms seems unlikely if colony social structure is a phenotypically plastic trait that varies within populations, with single- and multiple-queen colonies existing together.

\section{ACKNOWLEDGMENTS}

We thank L. Degen and C. Peter for technical assistance, N. Gyllenstrand for providing primers ahead of publication; J. Goudet for advice on statistics; and R. L. Hammond, L. Keller, J. S. Pedersen, and three anonymous reviewers for comments on the manuscript. This study was supported by grants from the Swiss National Science Foundation (3161934.00 to MC) and from the Herbette Foundation.

\section{Literature Cited}

Bourke, A. F. G., and N. R. Franks. 1995. Social evolution in ants. Princeton Univ. Press, Princeton, NJ.

Bourke, A. F. G., H. A. A. Green, and M. W. Bruford. 1997. Parentage, reproductive skew and queen turnover in a multiplequeen ant analysed with microsatellites. Proc. R. Soc. Lond. B 264:277-283.
Chapuisat, M. 1996. Characterization of microsatellite loci in Formica lugubris $B$ and their variability in other ant species. Mol. Ecol. 5:599-601.

Chapuisat, M., and L. Keller. 1999. Extended family structure in the ant Formica paralugubris: the role of the breeding system. Behav. Ecol. Sociobiol. 46:405-412.

Chapuisat, M., and R. Crozier. 2001. Low relatedness among cooperatively breeding workers of the greenhead ant Rhytidoponera metallica. J. Evol. Biol. 14:564-573.

Chapuisat, M., J. Goudet, and L. Keller. 1997. Microsatellites reveal high population viscosity and limited dispersal in the ant Formica paralugubris. Evolution 51:475-482.

Crozier, R. H., and P. Pamilo. 1996a. Evolution of social insect colonies: sex allocation and kin selection. Oxford Univ. Press, Oxford, U.K.

. 1996b. Sympatric speciation: one into two will go. Nature 383:574-575.

DeHeer, C. J., V. L. Backus, and J. M. Herbers. 2001. Sociogenetic responses to ecological variation in the ant Myrmica punctiventris are context dependent. Behav. Ecol. Sociobiol. 49: 375-386.

Evans, J. D. 1996. Queen longevity, queen adoption, and posthumous indirect fitness in the facultatively polygynous ant Myrmica tahoensis. Behav. Ecol. Sociobiol. 39:275-284.

Forel, A. 1920. Les fourmis de la Suisse. Imprimerie coopérative, La Chaux-de-Fond, Switzerland.

Goodnight, K. F., and D. C. Queller. 1999. Computer software for performing likelihood tests of pedigree relationship using genetic markers. Mol. Ecol. 8:1231-1234.

Goropashnaya, A. V., P. Seppä, and P. Pamilo. 2001. Social and genetic characteristics of geographically isolated populations in the ant Formica cinerea. Mol. Ecol. 10:2807-2818.

Gösswald, K. 1989. Die Waldameise. Band 1. Biologische Grundlagen, Ökologie und Verhalten. Aula-Verlag, Wiesbaden, Germany.

Gyllenstrand, N., P. J. Gertsch, and P. Pamilo. 2002. Polymorphic microsatellite DNA markers in the ant Formica exsecta. Mol. Ecol. Notes 2:67-69.

Hamilton, W. D. 1964. The genetical evolution of social behaviour. II. J. Theor. Biol. 7:17-52.

Heinze, J., and L. Keller. 2000. Alternative reproductive strategies: a queen perspective in ants. Trends Ecol. Evol. 15:508-512.

Herbers, J. M. 1986. Nest site limitation and facultative polygyny in the ant Leptothorax longispinosus. Behav. Ecol. Sociobiol. 19: $115-122$.

. 1993. Ecological determinants of queen number in ants. Pp. 262-293 in L. Keller, ed. Queen number and sociality in insects. Oxford Univ. Press, Oxford, U.K.

Herbers, J. M., and V. S. Banschbach. 1999. Plasticity of social organization in a forest ant species. Behav. Ecol. Sociobiol. 45: $451-465$

Hochberg, M. E., B. Sinervo, and S. P. Brown. 2003. Socially mediated speciation. Evolution 57:154-158.

Hölldobler, B., and E. O. Wilson. 1977. The number of queens: an important trait in ant evolution. Naturwissenschaften 64:8-15. 1990. The ants. Springer-Verlag, Berlin.

Ingram, K. K. 2002. Plasticity in queen number and social structure in the invasive Argentine ant (Linepithema humile). Evolution 56:2008-2016.

Keller, I., and J. Zettel. 2001a. Contribution to the autoecology of Formica selysi Bondroit, 1918 (Hymenoptera, Formicidae) in a mature steppe and a newly created alluvial zone at Pfynwald (Switzerland): I. Feeding ecology. Mitt. Schweiz. Entomol. Ges. 74:183-193.

2001b. Contribution to the autoecology of Formica selysi Bondroit, 1918 (Hymenoptera, Formicidae) in a mature steppe and a newly created alluvial zone at Pfynwald (Switzerland): II. Habitat use. Mitt. Schweiz. Entomol. Ges. 74:227-236.

Keller, L. 1995. Social life: the paradox of multiple-queen colonies. Trends Ecol. Evol. 10:355-360.

. 1998. Queen lifespan and colony characteristics in ants and termites. Insectes Soc. 45:235-246. 
Keller, L., and M. Genoud. 1997. Extraordinary lifespans in ants: a test of evolutionary theories of ageing. Nature 389:958-960.

Keller, L., and K. G. Ross. 1998. Selfish genes: a green beard in the red fire ant. Nature 394:573-575.

Keller, L., and M. Chapuisat. 2002. Eusociality and cooperation. Encyclopedia of Life Sciences. Available at http://www.els.net. Nature Publishing Group, London.

Krieger, M. J. B., and K. G. Ross. 2002. Identification of a major gene regulating complex social behavior. Science 295:328-332.

Legendre, P., and M.-J. Fortin. 1989. Spatial pattern and ecological analysis. Vegetatio 80:107-138.

Lewis, P. O., and D. Zaykin. 1999. Genetic data analysis: computer program for the analysis of allelic data. Version 1.0 (d12). Available at http://lewis.eeb.uconn.edu/lewishome/software.html.

Lude, A., M. Reich, and H. Plachter. 1999. Life strategies of ants in unpredictable floodplain habitats of Alpine rivers (Hymenoptera: Formicidae). Entomol. Gener. 24:75-91.

Nonacs, P. 1988. Queen number in colonies of social Hymenoptera as a kin-selected adaptation. Evolution 42:566-580.

Pamilo, P. 1982. Genetic population structure in polygynous Formica ants. Heredity 48:95-106.

— 1 1983. Genetic differentiation within subdivided populations of Formica ants. Evolution 37:1010-1022.

. 1991a. Evolution of colony characteristics in social insects. II. Number of reproductive individuals. Am. Nat. 138:412-433. . 1991b. Life span of queens in the ant Formica exsecta. Insectes Soc. 38:111-119.

Pamilo, P., P. Gertsch, P. Thorén, and P. Seppä. 1997. Molecular population genetics of social insects. Annu. Rev. Ecol. Syst. 28: $1-25$.

Pedersen, J. S., and J. J. Boomsma. 1999a. Effect of habitat saturation on the number and turnover of queens in the polygynous ant, Myrmica sulcinodis. J. Evol. Biol. 12:903-917.

1999b. Genetic analysis of colony structure in polydomous and polygynous ant populations. Biol. J. Linn. Soc. 66:115-144.

Queller, D. C., and K. F. Goodnight. 1989. Estimating relatedness using genetic markers. Evolution 242:258-275.

Raymond, M., and F. Rousset. 1995. Genepop (version 1.2): population genetics software for exact tests and ecumenicism. J. Hered. 86:248-249.

Rosengren, R., L. Sundström, and W. Fortelius. 1993. Monogyny and polygyny in Formica ants: the result of alternative dispersal tactics. Pp. 308-333 in L. Keller, ed. Queen number and sociality in insects. Oxford Univ. Press, Oxford, U.K.

Ross, K. G. 1997. Multilocus evolution in fire ants: effects of selection, gene flow and recombination. Genetics 145:961-974
2001. Molecular ecology of social behaviour: analyses of breeding systems and genetic structure. Mol. Ecol. 10:265-284.

Ross, K. G., and L. Keller. 1998. Genetic control of social organization in an ant. Proc. Natl. Acad. Sci. USA 95:14232-14237.

Ross, K. G., M. J. B. Krieger, D. D. Shoemaker, E. L. Vargo, and L. Keller. 1997. Hierarchical analysis of genetic structure in native fire ant populations: results from three classes of molecular markers. Genetics 147:643-655.

Ross, K. G., D. D. Shoemaker, M. J. B. Krieger, C. J. DeHeer, and L. Keller. 1999. Assessing genetic structure with multiple classes of molecular markers: a case study involving the introduced fire ant Solenopsis invicta. Mol. Biol. Evol. 16:525-543.

Rüppell, O., M. Stratz, B. Baier, and J. Heinze. 2003. Mitochondrial markers in the ant Leptothorax rugatulus reveal the population genetic consequences of female philopatry at different hierarchical levels. Mol. Ecol. 12:795-801.

Seppä, P. 1994. Sociogenetic organization of the ants Myrmica ruginodis and Myrmica lobicornis: number, relatedness and longevity of reproducing individuals. J. Evol. Biol. 7:71-95.

Seppä, P., and P. Pamilo. 1995. Gene flow and population viscosity in Myrmica ants. Heredity 74:200-209.

Seppä, P., L. Sundström, and P. Punttila. 1995. Facultative polygyny and habitat succession in boreal ants. Biol. J. Linn. Soc. 56 533-551.

Shoemaker, D. D., and K. G. Ross. 1996. Effects of social organization on gene flow in the fire ant Solenopsis invicta. Nature 383:613-616.

Sundström, L. 1993. Genetical population structure and sociogenetic organisation in Formica truncorum. Behav. Ecol. Sociobiol. 33:345-354

Sundström, L., L. Keller, and M. Chapuisat. 2003. Inbreeding and sex-biased gene flow in the ant Formica exsecta. Evolution 57: $1552-1561$.

Suzuki, Y., and Y. Iwasa. 1980. A sex ratio theory of gregarious parasitoids. Res. Popul. Ecol. 11:366-382.

van der Hammen, T., J. S. Pedersen, and J. J. Boomsma. 2002. Convergent development of low-relatedness supercolonies in Myrmica ants. Heredity 89:83-89.

Weir, B. S. 1996. Genetic data analysis II. Sinauer Associates, Sunderland, MA.

Weir, B. S., and C. C. Cockerham. 1984. Estimating F-statistics for the analysis of population structure. Evolution 38:1358-1370.

West-Eberhard, M. J. 1986. Alternative adaptations, speciation, and phylogeny. Proc. Natl. Acad. Sci. USA 82:1388-1392.

- 1989. Phenotypic plasticity and the origins of diversity. Annu. Rev. Ecol. Syst. 20:249-278.

Wright, S. 1943. Isolation by distance. Genetics 28:114-138.

Corresponding Editor: R. Harrison 